\title{
Misconceptions of the Students with High Mathematical Creative Thinking Level in Solving the Geometric Shapes Problems
}

\author{
Hajjah Rafiah, Aminah Ekawati \\ STKIP PGRI \\ Banjarmasin, Indonesia \\ hajjahrafiah17@gmail.com
}

\begin{abstract}
Students are frequently wrong in understanding a certain concept or material in learning mathematics or termed as misconceptions. Misconceptions do not occur only at students with low mathematics skills or low levels of mathematical creative thinking, but also for students with high mathematical creative thinking. Therefore, it is important to describe the misconception of students' high mathematical creative thinking in solving the problems, especially geometric shapes problems because that is often overlooked. This research employed a qualitative approach and the data were presented descriptively. The study was conducted in SDI Surya Buana Malang in academic year 2015/2016. Four students from Class VI who fulfilled high mathematical creative thinking level were selected as the research subjects. Students with high mathematical creative thinking is students who have the problem solving skills in fluency, flexibility, and originality. The findings showed that the students with high mathematical creative thinking level had misconceptions in determining of the size of the parallelogram, determining of the perimeter of the combined shapes, and understanding the concept of square and rhombus.
\end{abstract}

Keywords: Misconception, Mathematical Creative Thinking, Geometric Shapes Problems

\section{INTRODUCTION}

Mathematics has an abstract study object in the form of facts, concepts, operations, and principles [1]. Due to its abstract concepts and deductive mindset, high-order thinking skill is needed to understand mathematics. This is why students have the perception that mathematics is a difficult and scary lesson. In fact, students encounter a lot of difficulties in learning mathematics [2]. In fact, students are frequently wrong in understanding a certain concept or material in learning mathematics.

Errors in understanding or perceiving a concept are called misconception. According to [3], misconception is conceptually based error. If it refers to [4], the term misconception can be understood as an "alternative concept", that is, the concept of science possessed by students, but different from the existing concepts of science. It means that the concept does not actually exist or wrong.

Misconception is different from errors although each gives incorrect results. Errors can occur due to student inaccuracy [5], [6]. This errors can also take the form of an error in understanding the concept or forgetting the settlement procedure, [6]. Thus, errors can occur because of misconceptions.

The emergence of misconceptions among students can be caused by two factors [7]. The first factor is because students interpret new experiences or concepts. The second factor is due to the emotional and intellectual misunderstanding that has been attached to students, so students find it difficult to accept new concepts that are different from their understanding [8] [7].

There are several causes of misconceptions in mathematics learning presented by [9], as follows. (1) Students are not ready to accept mathematics materials; (2) Mathematics is only for gifted children in mathematics; (3) Simply learn simple numbers and shapes; (4) Learning languages and literacy are more important than learning mathematics; (5) Teachers must provide a quality learning environment; (6) Mathematics should not be taught as an independent subject; (7) Mathematics assessment is not relevant to children; (8) Children learn mathematics only with concrete objects; (9) Computer cannot be used in learning mathematics.

Misconceptions do not occur only at students with low mathematics skills or low levels of mathematical creative thinking. The results of [10] study show that students with high levels of mathematical creative thinking have wrong understanding on the concept of perimeter and the extent of a plane figure. This discovery is not only found at one creative student, but there are some students who mathematically fall into the creative category indicate the same thing.

\section{METHODS}

This study is a descriptive study with qualitative approach. In this study, the researchers act as the main instrument. Researchers went directly to the field to dig and collect the necessary information.

This study was conducted in SDI Surya Buana Malang in the academic year 2015/2016. The research subjects selected in this study were four students of class VI who met the level of high mathematical creative thinking, but experiencing misconceptions in solving the problem of plane figure geometry. The level of mathematical creative thinking was determined based on the results of problem solving done by the students, namely fulfilling the aspect of fluency, flexibility, and originality [11] [10].

The researchers employed protocols that served as a tool for collecting data. The protocols were in the form of 
problem solving sheets and interview guides. The problem-solving sheet contained the tasks associated with a plane figure geometry as shown in Figure 1. The second procoler, the interview guide contained several questions that became the reference to the interview process. Questions on the interview could evolve according to the response given by the research subjects.

The data collection procedure was started by conducting interviews with four research subjects in turn. Each subject was asked to explain the problem solving previously given. Furthermore, task-based interviews were conducted to explore the misconceptions that occurred among the research subjects. Task-based interviewes done by giving some geometric problems to the subject of research related to the misconception that occurs on the subject. So, each subject can be given a different problems. It be functioning as source of triangulation.

\section{FINDINGS AND DISCUSSION}

Based on the aspects of mathematical creative thinking that arose in problem solving, namely fluency, flexibility, and originality, some students met high mathematical creative thinking categories. However, there were some students who met the level of high mathematical creative thinking had misconception in understanding and solving geometry problems. The misconceptions occured on some issues related to two demensional shapes. A detailed explanation is described in the next paragraph.

The first misconception was found in some students with high mathematically creative thinking, namely misunderstanding the concept of long sides on a parallelogram. According to the first subject and second subject, the oblique sides of the parallelogram was equal to the height. Thus, to determine the length of the hypotenuse of the parallelogram shown in Figure 1, the step was to calculate the square plot of the uppermost square plot to the bottom square plot vertically. This misconception raises an error in measuring the length of the hypotenuse that should be $10 \mathrm{~cm}$ becoming $8 \mathrm{~cm}$.

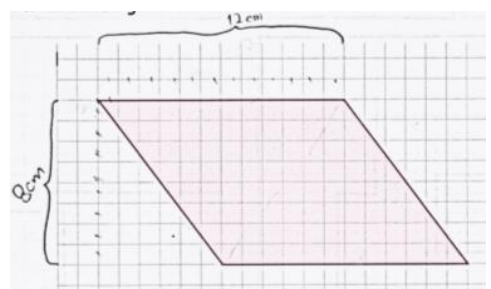

Fig 1. The oblique side is equal to the height of parallelogram

When asked to describe another parallelogram and its size, they still provided the same size between the height of the parallelogram and the length of the hypotenuse of the parallelogram. Figure 2 below is an example of an answer given by the second research subject.

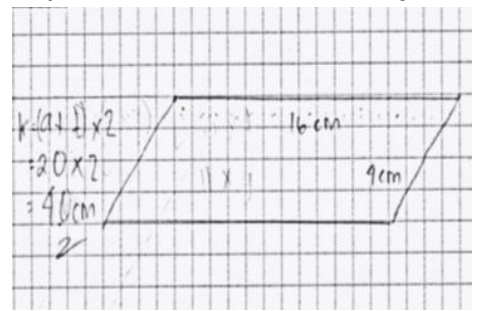

Fig 2. The new parallelogram made by the second subject
The third subject also understood that the height of parallelogram is equal to the hypotenuse of the parallelogram. According to him, if the oblique side of the parallelogram in Figure 2 is drawn straight, it would form a rectangle that has a size of $12 \times 8$. In fact, if the hypotenuse on the parallelogram is pulled straight to form the shape of the rectangle, then the correct size was $10 \mathrm{~cm}$, not $8 \mathrm{~cm}$. It also indicates that the third subject also had misconception in understanding the size of the hypotenuse of the parallelogram.

On the other hand, the fourth subject could determine the size of the parallelogram's oblique side correctly, but was mistaken in the process of determining its size. This happened because the fourth subject counted the hypotenuse of the parallelogram by calculating the square plots that according to the fourth subject was large. Since the parallelogram was drawn on the paper, the hypotenuse of the parallelogram cut several square plots so that the plots were not full. Some of the non-full plots were large and some were small. The non-full large square plots were called by the fourth subject as a plot representing one $\mathrm{cm}^{2}$ to calculate the size of the hypotenuse of the parallelogram.

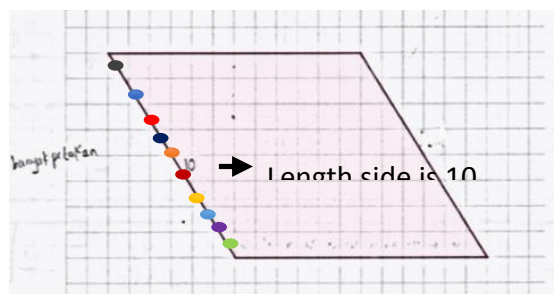

Fig 3. The length of oblique side based on the unit of millimeter block which was considered large by the fourth subject

The second misconception which was found in students with high mathematical creative thinking was misunderstanding in determining the perimeter of the combined shapes. When the third subject was asked to make some shapes with about $40 \mathrm{~cm}$ in perimeter, Figure 3 below shows the answer given by the third subject.

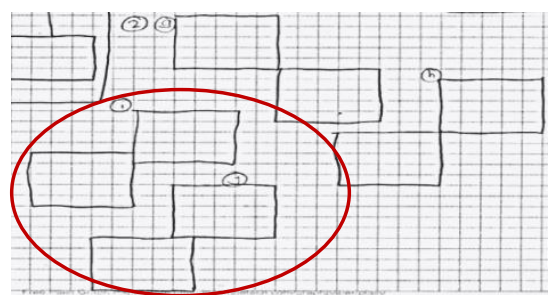

Fig 4. Combined shapes made by the third subject

According to Figure 4, two combined shapes which were given red mark did not have a perimeter of $40 \mathrm{~cm}$, while the other two had a perimeter of $40 \mathrm{~cm}$. The result of the interview with the third subject showed that the four combined shapes that he made each consisted of two rectangles having a perimeter of $20 \mathrm{~cm}$. The third subject counted only the perimeter of the combined figure he first made. Three other combined figures were created simply by changing the position of the first two rectangles. The reason the third subject did so was to get some shapes with perimeter of $40 \mathrm{~cm}$ in a short time. However, due to the mosconception of a combined shapes' perimeter, the third subject made random position different from the two squares. 
The third misconception emerged was the error in understanding the concept of square and rhombus. Based on the results of the interview, the fourth subject understood that the square is a long plane figure with equal sides and similar shape as in Figure 5a. If the square is rotated as far as $45^{\circ}$ as in Figure $5 \mathrm{~b}$, the fourth subject considered that the shapes is no longer a square, but becomes a rhombus.

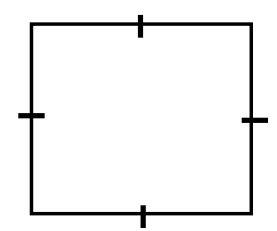

(a) Snilare

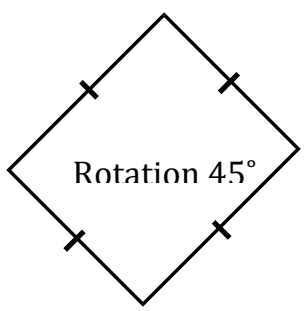

(b) Not square
Fig 5. Misconception from the fourth subject

The causes of misconceptions that occur in students with high mathematical creative thinking ability can be influenced by various factors. These factors can come from internal or external factors. Internal factors can be viewed from the students themselves, such as readiness or maturity to accept mathematics, student learning styles, students' perceptions of mathematics or the inability to capture material resulting from learning disabilities. Meanwhile, external factors can be seen from the learning environment or other environment outside the students themselves.

The emergence of misconceptions in understanding the length of the oblique side on a parallelogram and the perimeter of the combined shapes can be caused by the students' error in constructing the knowledge of the plane figure geometry they have learned. On the problemsolving sheet, only plane figure was drawn on the millimeter block paper, without the size of each side of the parallelogram. This makes it difficult for students to determine the exact length of the oblique sides of the parallelogram because the sides are not on the vertical or horizontal axis of the paper. As a result, students equate the size of the sides with the height. This case also applies to the perimeter of the combined shapes. Combined shapes consisting of multiple equal or different shapes will have the same perimeter even if their position is changed.

The students' error in understanding that a square that is rotated to the extent of any degree will remain squareshaped can be the students' error in constructing the knowledge of the plane figure geometry they have learned. However, based on the results of classroom observation and student book analysis, teachers or books tend to make a square like in Figure 5a, while the rhombus figure is also always introduced as in Figure 5b. This will build a misconception on the students. This will interfere with the development of further side conceptual understanding [12] [13].

\section{CONCLUSIONS AND SUGGESTIONS}

The results of this study showed that students with high mathematical creative thinking also experienced misconception in solving mathematical problems, especially plane figure goemetry. There were three misconceptions found as follows. (1) The students experienced misconception in understanding the length of the parallelogram sides, especially the oblique sides. The students asserted that if the size of the oblique sides of the parallelogram is equal to the height; (2) The students had incorrect understanding on the size of one unit on the millimeter block paper (strimin); (3) The students experienced misconception in understanding the concept of square and rhombus. If the square figure is rotated a few egrees resembling the shape of a rhombus, then the square figure is turned into a rhombic figure.

In order to avoid misconceptions in mathematics learning, teachers are expected to recognize misconceptions occuring among students as early as possible. Teachers must have knowledge about misconceptions, difficulties or errors made by students in understanding a certain concept or rules in learning mathematics. It means that a teacher should be sensitive and caring if there are students who may have misconceptions in their classes.

Effective learning will certainly have a positive impact on students. Teachers must plan and prepare learning that enables students to achieve basic competencies as well as enjoyment. Improper planning will lead to failure of classroom learning, especially if it leads to misconceptions among students. In other words, teachers are required to be good planners and managers of learning so as not to be one of the causes of misconceptions that occur among students.

\section{REFERENCES}

[1] H. Hudojo, Pengembangan Kurikulum dan Pembelajaran Matematika., Malang: UM Press, 2005.

[2] J. L. Booth, " Why Can't Students Get the Concept of Math?," Perspective on Language and Literacy,, vol. 37, no. 2, pp. 31-35, 2011

[3] Li, X.; Li, Y. , "Research on Students' Misconceptions to Improve Teaching and Learning in School Mathematics and Science.," Research in Brief,, vol. 108, no. 1, pp. 4-7, 2008.

[4] Burgoon, J.N., Heddle, M.L., Duron,, " Re-Examining the Similarities between Teacher and Student Conceptions about Physical Science.," Journal of Science Teacher Education, vol. 22, no. 2, pp. 101-114, 2011.

[5] L. Khazanov, "Adressing Students' Misconception about Probability During the First Years of Collage.," Mathematics and Computer Education, vol. 42, no. 3, pp. 180-192, 2007.

[6] A. Veloo; H. N. Krishnasamy; W. S. W. Abdullah, "Types of Student Errors in Mathematical Symbols, Graphs and ProblemSolving.," Asian Social Science , vol. 15, no. 15, pp. 324-334, 2015.

[7] R. G. Mohyuddin; U. Khalil., "Misconceptions of Students in Learning Mathematics at Primary Level.," Buletin of Education and Research, vol. 38, no. 1, pp. 133-162, 2016.

[8] S. Bull, T.J. Jackson; M.J. Lancaster, " Students' Interest in Their Misconceptions in First-Year Electrical Circuit and Mathematics Course.," International Journal of Electrical Engineering Education, vol. 47, no. 3, pp. 307-318, 2010.

[9] Lee, J.S.; Ginsburg, H.P., "Early Childhood Teachers' Misconceptions about Mathematics Education for Young Children in the United States.," Australasian Journal of Early Childhood, , vol. 34, no. 4, pp. 37-45, 2009.

[10] H. Rafiah, "Profil Berpikir Kreatif Matematis Siswa Kelas VI berdasarkan Gender dalam Pemecahan Masalah Matematika, Thesis tidak diterbitkan.," Pasca Sarjana UM, Malang, 2016.

[11] L. E. Mann, "The Search for Mathematical Creativity: Identifying 
Creative Potential in Middle School Students.," Creativity Research Journal, vol. 21, no. 4, pp. 338-348, 2009.

[12] Russel, M, O’Dwyer, L.M., Miranda, H. , "Diagnosing Students' Misconceptions in Algebra: Results from An Experimental Pilot Study.," Behavior Research Methods, vol. 41, no. 2, pp. 414-424, 2009.

[13] Kula, S. ;Güzel, E.B. , "Misconceptions Emerging in Mathematics Student Teachers' Limit Instruction and Their Reflections.," Springer, vol. 48, p. 3355=3372, 2014. 